\title{
Scale Insect Records from Ornamental Plants Help to Prioritize Plant Health Resource Development
}

\author{
William E. Klingeman, ${ }^{1,+}$ Juang-Horng Chong, ${ }^{2}$ Carrie Harmon, ${ }^{3}$ Lisa Ames, ${ }^{4}$ Anthony V. LeBude, ${ }^{5}$ and Predeesh Chandran ${ }^{6}$ \\ ${ }^{1}$ Plant Sciences Department, The University of Tennessee, Knoxville, TN 37996 \\ ${ }^{2}$ Department of Plant and Environmental Sciences, Clemson University, Pee Dee Research and Education Center, Florence, SC 29506 \\ ${ }^{3}$ Department of Plant Pathology, University of Florida, UF Plant Diagnostic Center, Gainesville, FL 32611 \\ ${ }^{4}$ Homeowner Insect and Weed Diagnostics Laboratory, University of Georgia - Griffin Campus, Griffin, GA 30223 \\ ${ }^{5}$ Department of Horticultural Science, Mountain Horticultural Crops Research and Extension Center, NC State University, Mills River, NC 28759 \\ ${ }^{6}$ Plant and Pest Diagnostic Clinic, Clemson University, Pendleton, SC 29670
}

Accepted for publication 4 August 2020.

\section{Abstract}

Estimates about which scale insect species are most frequently encountered in U.S. landscapes and commercial production systems are largely anecdotal. This survey of records maintained across about 15 years within the National Plant Diagnostic Network (NPDN) National Data Repository (NDR) returned information from 10,671 records of 192 scale insect species and 23 suspected species that were associated with ornamental plants. This broad species diversity challenges our ability to effectively train diagnosticians, can confound species identification accuracy, and impedes outreach efforts and resource development. To help focus future efforts in the development of outreach resources and diagnostic training guides, lists were assembled that identified the 60 top-ranked soft, armored, mealybug, and other scale insect taxa most frequently diagnosed within NDR records. Diagnostic service records from Georgia, North Carolina, South Carolina, and Tennessee provided more extensive information regarding sites or client types from which submitted samples originated. Results are being used to develop web-based, image-rich guides to key scale insect taxa in the southeastern United States that will explain life cycles, behaviors, and biology for pest species. These web-based guides can be exploited to optimize pest management actions.

Keywords: scale insects, diagnostics, entomology, landscape plants, National Plant Diagnostic Network
Scale insects (Hemiptera: Sternorrhyncha: Coccoidea) cause significant economic losses to agronomic and horticultural crops worldwide. Oetting et al. (2007) estimated that crop losses and costs of control for scale insects on ornamental plants amounted to \$45.5 million in Georgia (GA), U.S.A., alone, whereas Kosztarab (1997) estimated the costs to exceed $\$ 1$ billion annually worldwide. These losses accrue through food quality, plant growth and yield reductions, and eventually mortality resulting from severe and sustained nutrient removal and cell destruction. Honeydew and sooty mold associated with infestations by some scale insect families can lead to physiological decline of plant quality, aesthetic damage, and associated cost for management efforts (e.g., Braman et al. 2015).

\section{${ }^{\dagger}$ Corresponding author: W. Klingeman; wklingem@utk.edu}

Funding: This work was supported, in part, by the USDA National Institute of Food and Agriculture, Hatch projects 1009630: TEN00495 (W. E. Klingeman), SC1700468 (J. H. Chong), FLA-PLP-005179 (C. L. Harmon), and 1007367 (A. V. LeBude). Additional support was provided by USDA NIFA to NPDN (2016-3762025850) and J. H. Chong (2017-700006-27156).

*The $\boldsymbol{e}$-Xtra logo stands for "electronic extra" and indicates there are supplementary tables published online.

The author(s) declare no conflict of interest.

(C) 2020 The American Phytopathological Society
Ornamental plant growers ranked armored and soft scale pests as some of the most prevalent and difficult to control arthropod pests (Braman et al. 2015; Fulcher et al. 2012). Scale insects are also key arthropod pests affecting street trees in the southeastern United States (Frank 2019). Scale insect outreach resources, including guidelines for scale identification and management, were subsequently identified as a critical need to serve green industry professionals (Braman et al. 2015). Accurate identification of scale insect species is critical for understanding their life cycle, which in turn is important in targeting a susceptible life stage with effective insecticides and other management tools (Camacho and Chong 2015).

Green industry professionals may be receiving information and self-diagnosing scale insect problems using Extension service websites or other online resources. If so, development of these resources would ideally be focused on the most common scale insect species encountered on ornamental host plants. To date, however, anecdotal evidence has been the primary means of gauging which would be the key species (Raupp et al. 1992). There is a critical need in developing an accessible list of key scale insect species of ornamental plants based on actual records of detection and sample submission, instead of anecdotal evidence. Such products are timely because there is increasing evidence that scale insects are effectively exploiting urbanization and associated stressors and are becoming an even greater management challenge in response to these changes (Dale and Frank 2018; Hanks and Denno 1993; Tooker and Hanks 2000; Youngsteadt et al. 2015). 
To address this knowledge gap and to guide future Extension and outreach resource development efforts, the evaluation and analysis of database records reported here was undertaken to determine (i) the identities of scale insects that are most frequently diagnosed following submission to diagnosticians across the different National Plant Diagnostic Network (NPDN) contributing regions, and (ii) which types of users of state-based diagnostic services are submitting these samples for identification.

\section{Queries to NPDN's National Data Repository (NDR) Database}

Data used in this study were extracted from the NDR maintained for the NPDN. States, the District of Columbia, and territories identified from NDR data will be denoted in the remainder of this report by their postal code abbreviations. Established in 2002, the NPDN includes among its programmatic initiatives the coordination and maintenance of a national repository database of records of identifications made on endemic, emerging, and exotic pathogens and pests of agricultural, forest, and landscape plants in the United States (NPDN 2018a, 2018b; Stack et al. 2014). Diagnostic laboratories and experts across the United States submit their identifications based upon examinations of submitted physical samples and images conveyed to laboratories through distance diagnostics. Physical samples are assessed by appearance and are often examined microscopically. When sufficient time and expertise are available, scale insect specimens should be slide mounted for compound microscopic examination to enable differentiation of species morphology.

Participating states were partitioned into five contributing regions. The Southern Plant Diagnostic Network (SPDN) includes AL, AR, FL, GA, KY, LA, MS, NC, SC, TN, TX, VA, PR (Puerto Rico), and USVI (the U.S. Virgin Islands). Records from TX originally were divided into SPDN and Great Plains Diagnostic Network (GPDN) in the NDR database. To facilitate data management and to reflect the relative population density from where submissions were expected to occur, all TX records were tabulated within SPDN. The Northeastern Plant Diagnostic Network (NEPDN) includes CT, DC, DE, MA, MD, ME, NH, NJ, NY, PA, RI, VT, and WV. The North Central Plant Diagnostic Network (NCPDN) consists of IA, IL, IN, MI, MO, MN, OH, and WI. The Great Plains Diagnostic Network (GPDN) includes CO, KS, MT, NE, ND, OK, SD, and WY (see above about records from TX). The Western Plant Diagnostic Network (WPDN) includes AK, AZ, CA, ID, NM, NV, OR, UT, WA, HI, and AS (American Samoa).

Scale insect diagnostic records in NDR are available as early as November 2004, but regular submissions only began in 2005 . Therefore, we examined records from 2005 to 2017 . The database was queried by genus name (taxonomic status validated by comparing to ScaleNet online database by Garcia Morales et al. [2016]). All resulting records that provided county locality and state, district, or territory information, dates for sample collection, observation, and data entry, common and scientific names for host plant and pest, species determination method (if any), a pest confidence measure (as confirmed, suspected, inconclusive, or not detected), and client types (if any) were compiled. Each specimen also included a unique record identification number, but no other submitter or source-oforigin data were provided. Data were subdivided among all noted species occurring within the genus, as well as a category of identifications made no further than to the generic level. Records for which a "not detected" determination was returned were excluded from analyses. A few records indicated that the generic or species identities were inconclusive; to facilitate tabulation those records were coded among tallies of suspected identity. Queries to NDR returned 10,671 useful diagnostic records.

With verified identification and client type data (i.e., whether the samples originated from a homeowner, nursery, or greenhouse grower), we hope to develop clientele-targeted Extension and diagnostic tools for scale insect management. Client type notations are voluntary data fields within NDR, however, and may not be commonly documented by contributing diagnosticians. Preliminary queries reported that only $1.4 \%$ of NDR records included client type data. Thus, we elected not to examine the client types in NDR database due to the limited available sample size for records.

\section{Queries of Diagnostic Records from Four}

Southeastern States

In order to document the major sources of scale insect sample submissions, we queried diagnostic records from four state university-based diagnostic databases in GA, NC, SC, and TN as case studies. These diagnostic services are the University of Georgia's Homeowner Insect and Weed Diagnostic Laboratory and the Extension Entomology Laboratory in Griffin and Athens, GA; North Carolina State University's Plant Disease and Insect Clinic in Raleigh, NC; Clemson University's Plant and Pest Diagnostic Clinic in Pendleton, SC; and the Soil, Plant Pest and Disease Lab and diagnosticians associated with the University of Tennessee in Nashville and Knoxville, TN.

The four case study states yielded 1,462 scale insect records, spanning a range of 9 to 15 years: GA (2002 to 2016; 416 records), NC (2008 to 2016; 439 records), SC (2007 to 2016; 334 records), and TN (2005 to 2016, 276 records). When listed, client types were grouped into the following categories: residential/homeowner; commercial landscaper/arborist that also included lawn care; golf course and athletic field submissions; commercial growers that included submissions from nursery, greenhouse, orchard/vineyard, and garden centers; regulatory/Extension submissions; and farmsourced plus other commercial (e.g., plantation), municipal, and park/natural area submissions.

\section{Most Frequently Diagnosed Scale Insect Species}

A total of 192 confirmed scale insect species, 23 suspected species, and 27 genus-only identities provided by diagnosticians were included in the NDR (Table 1). These included 95 identified species, 10 suspected species, and 11 genus-only armored scales (Supplementary Table S1); 46 identified species, one suspected species, and eight genus-only soft scales (Supplementary Table S2); 38 identified species, 10 suspected species, and four genus-only mealybugs (Supplementary Table S3); and 13 identified species, two suspected species, and four genus-only scale insects in other scale families (Supplementary Table S4). Armored scale insects (Diaspididae) are the most frequently diagnosed family in all NPDN regions, followed by soft scales (Coccidae), mealybugs (Pseudococcidae), and other scale insect families (Table 1). Although some species are widely distributed, others are more restricted in their distribution among the states (Supplementary Table S5).

The frequencies of identifications were used to generate lists of the most frequently diagnosed 20 top-ranked armored scale taxa (Table 2), 20 top-ranked soft scale taxa (Table 3), 10 top-ranked mealybug taxa (Table 4), and five top-ranked other scale insect taxa (Table 5). Results reported in this survey differentiate taxa within confirmed, suspected, and inconclusive species, and genus-level only identities. Data provided within the supplementary tables can be used to develop lists of the taxa within scale insect families that 
are most frequently diagnosed for each NPDN region. For example, the 60 top-ranked scale insect taxa (represented by 51 species plus nine genus-level identities) that are listed across Tables 2, 3, 4, and 5 accounted for $31.3 \%$ of all scale insect taxa (and $86.7 \%$ of all submitted specimens) reported across all NPDN regions, or 54.0, $38.8,48.4,31.7$, and $35.8 \%$ of the scale insect taxonomic identities recorded among GPDN, NEPDN, NCPDN, SPDN, and WPDN, respectively (Supplementary Tables S1, S2, S3, and S4). The topranked taxa also accounted for $18.1 \%(84.5 \%), 40.0 \%(86.0 \%)$, $27.9 \%(94.1 \%)$, and $23.8 \%(75.8 \%)$ of all taxa (all submitted specimens) of armored scales, soft scales, mealybugs and other scale insects, respectively, at the NPDN level. These scale insect taxa are, therefore, considered the most commonly submitted, encountered, and important for research and Extension resource development.

\section{Client Types Contributing Samples for Scale Insect Diagnoses}

Comparing records from 2008 to 2016 that were available from all four case study states, the examinations of state diagnostic records (not shown) yielded an annual average of 24 ( \pm 3.5$)$ (range: eight records in 2011 to 43 in 2008) scale insect diagnoses in GA, 49 ( \pm 10.2) (range: 10 in 2011 to 108 in 2009) in NC, $35( \pm 2.8)$ (range: 19 in 2016 to 46 in 2013) in SC, and 22 ( \pm 3.1$)$ (range: nine

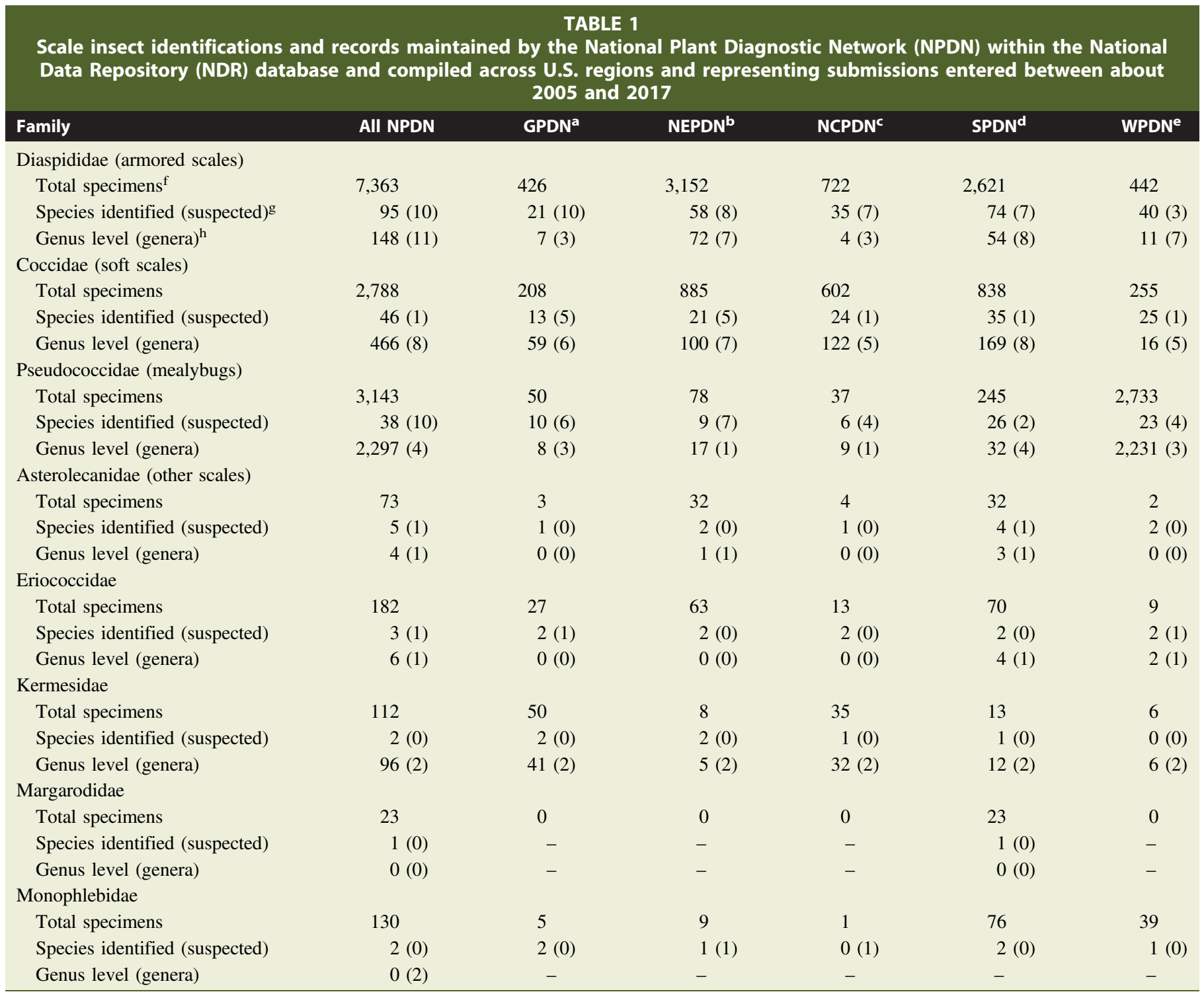

${ }^{\text {a }}$ Great Plains Diagnostic Network (GPDN): CO, KS, MT, NE, ND, OK, SD, TX*, and WY.

${ }^{\mathrm{b}}$ Northeastern Plant Diagnostic Network (NEPDN): CT, DE, MA, MD, ME, NH, NJ, NY, PA, RI, VT, and WV.

${ }^{\mathrm{c}}$ North Central Plant Diagnostic Network (NCPDN): IA, IL, IN, MI, MO, MN, OH, and WI.

d Southern Plant Diagnostic Network (SPDN): AL, AR, FL, GA, KY, LA, MS, NC, SC, TN, TX*, VA, PR (Puerto Rico), and USVI (U.S. Virgin Islands). Within the NPDN, Texas (TX*) is split between GPDN and SPDN. To facilitate data management and to reflect the majority population density from which submissions were expected to occur, all TX records were tabulated within SPDN.

e Western Plant Diagnostic Network (WPDN): AK, AZ, CA, HI, ID, NM, NV, OR, UT, WA, AS (American Samoa).

${ }^{\mathrm{f}}$ Total number of specimens.

g Number of species identified (number of additional species identities listed only as "suspected" or "inconclusive").

${ }^{\mathrm{h}}$ Number of specimens with genus-level only identification (number of genera within family represented by these specimens). 
TABLE 2

Twenty-one armored scale insect taxa (Hemiptera: Sternorrhyncha: Coccoidea: Diaspididae) ranking as the top 20 most frequent

among submissions to the National Plant Diagnostic Network (NPDN) and their respective regional data for submissions made between about 2005 and 2017

\begin{tabular}{|c|c|c|c|c|c|c|c|c|}
\hline \multirow[b]{2}{*}{ Rank } & \multirow{2}{*}{$\begin{array}{c}\text { Species and } \\
\text { taxonomic authority }\end{array}$} & \multirow{2}{*}{$\begin{array}{l}\text { NPDN } \\
\text { sum }^{a}\end{array}$} & \multicolumn{5}{|c|}{ Number of specimens (ID confirmed/suspected) } & \multirow{2}{*}{$\begin{array}{c}\text { Principal host } \\
\text { plant(s) indicated }\end{array}$} \\
\hline & & & GPDN ${ }^{b}$ & NEPDNc & NCPDN $^{d}$ & SPDN $^{\mathbf{e}}$ & WPDNf & \\
\hline 1 & $\begin{array}{l}\text { Chionaspis pinifoliae } \\
\text { (Fitch) }\end{array}$ & 758 & $198(113 / 85)$ & $183(141 / 42)$ & $263(192 / 71)$ & $47(44 / 3)$ & $67(63 / 4)$ & Many coniferous plants \\
\hline 2 & $\begin{array}{l}\text { Carulaspis juniperi } \\
\text { (Bouché) }\end{array}$ & 660 & $22(15 / 7)$ & $341(217 / 124)$ & $46(46 / 0)$ & $195(148 / 47)$ & $56(35 / 21)$ & $\begin{array}{l}\text { Chamaecyparis sp., } \\
\quad \times \text { Cupressocyparis sp., } \\
\text { Juniperus } \text { sp., Thuja sp. }\end{array}$ \\
\hline 3 & Fiorinia externa Ferris & 597 & - & $529(511 / 18)$ & $8(7 / 1)$ & $60(56 / 4)$ & - & Many deciduous plants \\
\hline 4 & $\begin{array}{l}\text { Lopholeucaspis japonica } \\
\text { (Cockerell) }\end{array}$ & 491 & $1(0 / 1)$ & $320(301 / 19)$ & $32(29 / 3)$ & $138(133 / 5)$ & - & Many deciduous plants \\
\hline 5 & $\begin{array}{l}\text { Unaspis euonymi } \\
\text { (Comstock) }\end{array}$ & 468 & $51(36 / 15)$ & $131(103 / 28)$ & $80(71 / 9)$ & $197(177 / 20)$ & $9(8 / 1)$ & Many deciduous plants \\
\hline 6 & Fiorinia theae Green & 427 & $1(0 / 1)$ & $173(172 / 1)$ & $2(0 / 2)$ & $251(243 / 8)$ & - & $\begin{array}{l}\text { Camellia sp., Ilex sp., } \\
\text { Illicium sp. }\end{array}$ \\
\hline 7 & $\begin{array}{l}\text { Melanaspis obscura } \\
\text { (Comstock) }\end{array}$ & 392 & $10(4 / 6)$ & $81(66 / 15)$ & $25(22 / 3)$ & $276(231 / 45)$ & - & Gleditsia sp., Quercus sp. \\
\hline 8 & $\begin{array}{l}\text { Lepidosaphes pallida } \\
(\text { Maskell })^{\mathrm{h}}\end{array}$ & 366 & $2(2 / 0)$ & $199(163 / 36)$ & $3(3 / 0)$ & $162(147 / 15)$ & - & Many coniferous plants \\
\hline 8 & Lepidosaphes ulmi (L.) & 366 & $66(45 / 21)$ & $129(90 / 39)$ & $129(104 / 25)$ & $32(22 / 10)$ & $10(9 / 1)$ & Many deciduous plants \\
\hline 9 & $\begin{array}{l}\text { Pseudaulacaspis prunicola } \\
\text { (Maskell) }\end{array}$ & 240 & - & $215(124 / 91)$ & $11(6 / 5)$ & $13(6 / 7)$ & $1(1 / 0)$ & Many deciduous plants \\
\hline 10 & $\begin{array}{l}\text { Aspidiotus cryptomeriae } \\
\text { Kuwana }\end{array}$ & 206 & - & $190(139 / 51)$ & $1(0 / 1)$ & $15(15 / 0)$ & - & Many coniferous plants \\
\hline 11 & $\begin{array}{l}\text { Pseudaulacaspis pentagona } \\
\text { (Targioni Tozzetti) }\end{array}$ & 201 & $2(2 / 0)$ & $55(32 / 23)$ & $1(1 / 0)$ & $139(98 / 41)$ & $4(4 / 0)$ & Many deciduous plants \\
\hline 12 & $\begin{array}{l}\text { Melanaspis tenebricosa } \\
\text { (Comstock) }\end{array}$ & 161 & $1(0 / 1)$ & $26(20 / 6)$ & $4(1 / 3)$ & $130(108 / 22)$ & - & $\begin{array}{l}\text { Acer sp., Ilex sp., Ulmus } \\
\text { sp. }\end{array}$ \\
\hline 13 & $\begin{array}{l}\text { Carulaspis minima } \\
\text { (Signoret) }\end{array}$ & 160 & $1(1 / 0)$ & $38(23 / 15)$ & $2(2 / 0)$ & $103(80 / 23)$ & $16(16 / 0)$ & Many coniferous plants \\
\hline 14 & $\begin{array}{l}\text { Comstockaspis perniciosa } \\
\text { (Comstock) (formerly } \\
\text { Diaspidiotus perniciosus) }\end{array}$ & 142 & $19(15 / 4)$ & $38(29 / 9)$ & $17(12 / 5)$ & $58(47 / 11)$ & $10(9 / 1)$ & Many deciduous plants \\
\hline 15 & $\begin{array}{l}\text { Hemiberlesia (formerly } \\
\text { Abgrallaspis) lataniae } \\
\text { (Signoret) }\end{array}$ & 123 & $13(12 / 1)$ & $22(11 / 11)$ & $4(3 / 1)$ & $62(46 / 16)$ & $22(22 / 0)$ & Many deciduous plants \\
\hline 16 & $\begin{array}{l}\text { Pseudaulacaspis cockerelli } \\
\text { (Cooley) }\end{array}$ & 119 & - & $6(6 / 0)$ & $2(1 / 1)$ & $88(78 / 10)$ & $23(20 / 3)$ & $\begin{array}{l}\text { Many deciduous plants, } \\
\text { Cycas sp., palms }\end{array}$ \\
\hline 17 & $\begin{array}{l}\text { Hemiberlesia (formerly } \\
\text { Abgrallaspis) ithacae } \\
\text { (Ferris) }\end{array}$ & 116 & - & $104(61 / 43)$ & $4(3 / 1)$ & $7(2 / 5)$ & $1(1 / 0)$ & Many coniferous plants \\
\hline 18 & Lepidosaphes pini (Maskell) & 80 & $1(1 / 0)$ & $68(50 / 18)$ & - & $9(8 / 1)$ & $2(2 / 0)$ & $\begin{array}{l}\text { Cryptomeria sp., Picea sp., } \\
\text { Pinus } \mathrm{sp} ., \text { Sciadopitys } \\
\text { verticillata }\end{array}$ \\
\hline 19 & Odonaspis ruthae Kotinsky & 77 & $2(1 / 1)$ & - & - & $73(52 / 21)$ & $2(2 / 0)$ & $\begin{array}{l}\text { Cynodon sp., Eremochloa } \\
\text { sp. }\end{array}$ \\
\hline 20 & $\begin{array}{l}\text { Chrysomphalus aonidum } \\
\text { (L.) }\end{array}$ & 73 & $1(1 / 0)$ & $21(16 / 5)$ & $2(1 / 1)$ & $42(35 / 7)$ & $7(6 / 1)$ & $\begin{array}{l}\text { Many deciduous and } \\
\text { coniferous plants }\end{array}$ \\
\hline
\end{tabular}

${ }^{a}$ NPDN maintains the National Data Repository (NDR) database that is a compilation of state-based submission records from plant pest and disease diagnostic clinics, including distance diagnostic submissions.

${ }^{\mathrm{b}}$ Great Plains Diagnostic Network (GPDN): CO, KS, MT, NE, ND, OK, SD, TX*, and WY.

${ }^{c}$ Northeastern Plant Diagnostic Network (NEPDN): CT, DE, MA, MD, ME, NH, NJ, NY, PA, RI, VT, and WV.

${ }^{\mathrm{d}}$ North Central Plant Diagnostic Network (NCPDN): IA, IL, IN, MI, MO, MN, OH, and WI.

${ }^{e}$ Southern Plant Diagnostic Network (SPDN): AL, AR, FL, GA, KY, LA, MS, NC, SC, TN, TX*, VA, PR (Puerto Rico), and USVI (U.S. Virgin Islands). Within the NPDN, Texas (TX*) is split between GPDN and SPDN. To facilitate data management and to reflect the majority population density from which submissions were expected to occur, all TX records were tabulated within SPDN.

${ }^{\mathrm{f}}$ Western Plant Diagnostic Network (WPDN): AK, AZ, CA, HI, ID, NM, NV, OR, UT, WA, AS (American Samoa).

${ }^{\mathrm{g}}$ Information provided about principal host plants does not reflect the documented range of possible host plants, and instead denotes the host plants that were most frequently indicated on data records that accompanied scale insect submissions.

h Species tally includes 17 specimens of "L. maskelli" (IRAKHOA), now classified as Lepidosaphes pallida (Maskell). 
in 2008 to 37 in 2012) in TN. Across this uniform 9-year timespan, the frequency of submissions varied considerably from the types of clients who submitted diagnostic samples that yielded scale insect identifications (Fig. 1). Private homeowners submitted the largest share of the scale insect samples to these case study state diagnostic services (about $54 \%$ in GA, $70 \%$ in $\mathrm{NC}, 62 \%$ in SC, and $62 \%$ in $\mathrm{TN}$ ), followed by landscape care professionals and arborists (about $27 \%$ in GA, $12 \%$ in NC, $28 \%$ in SC, and $32 \%$ in TN). Commercial growers (including nursery producers, orchardists, and retailers) submitted about $2 \%$ of the samples in GA, $12 \%$ in $\mathrm{NC}, 5 \%$ in SC, and $4 \%$ in TN. Regulatory and Extension agents, farmers, and other clients of the state diagnostic services each contributed $<5 \%$ of the samples.

\section{Priorities for Scale Insect Management \\ Resource Development}

Our goal for this survey of existing records of scale insect diagnoses is to develop a list of key species that will guide development of diagnostic and Extension resources. Priority will be given to the most frequently diagnosed scale insect taxa (Tables 2 , 3,4 , and 5) that are most frequently represented among samples submitted by homeowners and green industry professionals across all NPDN regions. The 10,671 records from NDR that we examined give confidence that a reasonably exhaustive list of scale insect taxa encountered on ornamental plant species in both landscape and production systems has been assembled.

Distribution information regarding states from which scale insect taxa are reported (Supplementary Table S5) is not intended to be a comprehensive account, neither by state nor by species. In fact, these data reflect only about the 15 most recent years for which state diagnostic records have been entered into the NDR database. These findings can complement and direct future efforts to delineate U.S. distribution records that are compiled by taxonomists for species within ScaleNet (Garcia Morales et al. 2016). For example, where conflicting or questionable records exist, this survey of NDR records can assist to direct additional regionally targeted detection or surveying efforts necessary to validate diagnostic identifications.

Few records were submitted for scale insect samples that originated in states and territories that are noncontiguous with the lower 48 U.S. states (i.e., AK, AS, HI, PR, and USVI). NDR records yielded just 45 armored scale, 31 soft scale, and 48 mealybug submissions from noncontiguous locations (data not shown). Alaska, in which very few scale insect taxa are documented (Maw et al. 2000), did not submit any specimens. The Hawaiian Islands host a diverse assemblage of scale insects (Nakahara 1981); however, just $95 \mathrm{NDR}$ records from HI were included during this 15 -year period.

Conclusions drawn from databases of identification records may be limited by the accuracy of identification and identifier expertise. Identification of scale insect species in particular can depend upon highly specialized knowledge (Deng et al. 2016) and, consequently, can be a limited skillset among diagnosticians. The NDR database does not provide data on the expertise of diagnosticians and the accuracy of species-level identification. A lack of such data inevitably casts doubt on this survey's list of priority taxa and recommendations. Despite the obvious shortcoming, the list of priority taxa generated across NPDN regions coincides with anecdotal reports and indeed aligns with the most common species that author J.-H. Chong and others have often encountered and worked to diagnose in our capacity as Extension specialists in the region.

Many diagnosticians who are not initially trained as scale insect or homopteran taxonomists may gain basic knowledge of scale insect identification through trainings provided to first responders by NPDN (NPDN 2018b). Aptitude of diagnosticians increases with exposure to specimens and different species across time. Direct taxonomic and diagnostic expertise with scale insect identification, however, may be less available at universities as senior staff and faculty seek new opportunities and experiences, including retirement (Hardy 2013). Diagnosticians who are not as well trained or who have less experience in scale insect identification may not be able to identify or may not have confidence in identifying scale insect specimens to species. A consequence of this skill gap is a relatively large number of tentative or suspected identifications, in which $20.4,23.6,3.9$, and $16.7 \%$ of armored scale, soft scale, mealybug, and other scale insect records, respectively, were given suspected or tentative identities across all NPDN regions (Supplementary Tables S1, S2, S3, and S4).

The numbers of suspected or tentative identifications also differed among states and NPDN regions. In general, among the NPDN regions, GPDN is the most conservative and WPDN is the most confident in accuracy about identifications of scale insects (Supplementary Tables S1, S2, S3, and S4). The reason for limited diagnostic certainty from some states, territories, or regions may reflect a lack of taxonomic expertise or a low level of voluntary data submission to NDR from these areas. Additional training opportunities focusing on the taxa with the greatest numbers of tentative identifications (e.g., armored and soft scales) and NPDN regions (e.g., GPDN) would be expected to increase the expertise and confidence of diagnosticians. Greater recognition of common scale insect species will also help diagnosticians and first responders discriminate which submitted specimens are uncommon or may be of concern as potential new and nonnative pest introductions.

We caution that future diagnostic resources and identification aids must be developed with care taken to highlight challenges inherent in identifying species that share highly similar morphological characters and host plant resources. For example, Ceroplastes pseudoceriferus Green is not thought to have established in the United States. This species has an extensive host plant range that overlaps with that of Ceroplastes ceriferus (F.), which it closely resembles (Hamon and Williams 1984), and so poses a high probability of being overlooked during routine diagnostic examination. Similarly, Chionaspis pinifoliae, which is morphologically similar to $C$. heterophyllae, requires slide mounting to make informative characteristics visible using compound microscopy. Misidentification of these species can confound research findings, lead to economic losses, and confuse effective regulatory guidance (Ahmed and Miller 2019). Resources developed for these invasive or difficult-to-distinguish species may include guidelines on the lowest taxonomic level of identification that can reasonably be achieved by stereoscopic versus microscopic examination. In some cases, requirement for more detailed microscopy using slidemounted specimens or molecular techniques, or redirection for examination by specialists, may be necessary. When these additional efforts are undertaken, added value will accrue in helping to provide more accurate and detailed distribution maps of where these species are found.

Even a tentative diagnosis can be useful in cases in which management actions would be similar for closely related species and species that occupy a similar feeding niche. Often by the time a homeowner or green industry professional submits scale insect samples for identification, the pest populations have caused aesthetic injury to ornamental plants, and curative treatment with insecticides is needed. To be most effective, scale insect management requires timely application of insecticides that target crawlers and young nymphs, which are the most vulnerable life stages, but which occur at different times of year and last for 
different durations depending upon scale insect species as well as interactions within different habitats (e.g., Camacho and Chong 2015; Dale and Frank 2014; Miller and Davidson 2005; Quesada and Sadof 2017; Quesada et al. 2018). Camacho and Chong (2015) concluded that for some genera (e.g., Parthenolecanium), congenerics have relatively similar life cycles, in terms of voltinism, seasonal emergence timing, and duration of crawler emergence, whereas species in other genera (e.g., Ceroplastes) have very

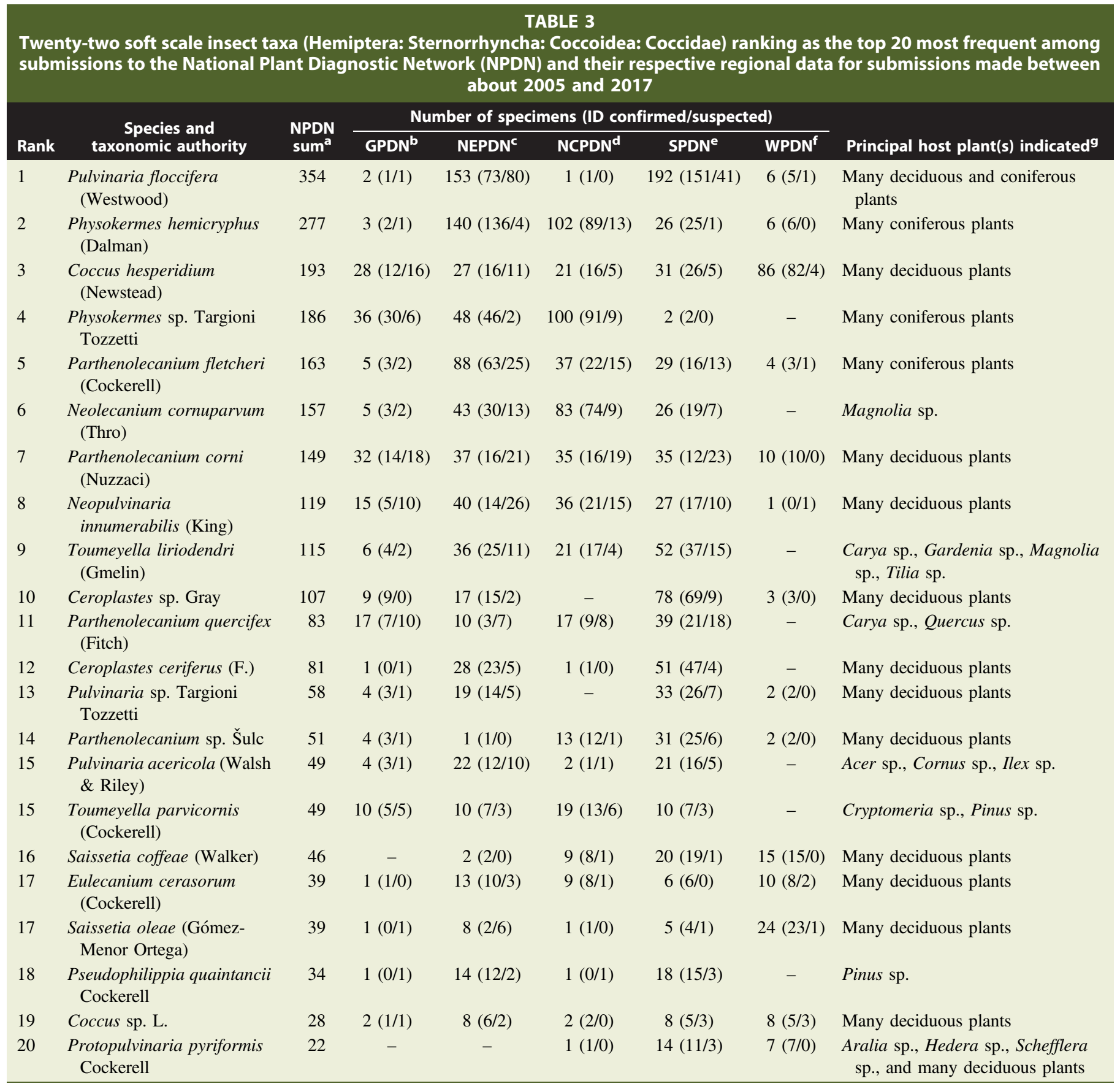

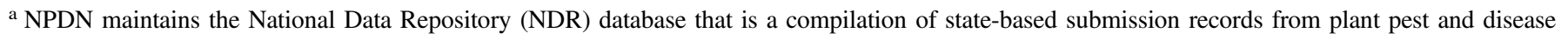
diagnostic clinics, including distance diagnostic submissions.

${ }^{\mathrm{b}}$ Great Plains Diagnostic Network (GPDN): CO, KS, MT, NE, ND, OK, SD, TX*, and WY.

${ }^{\mathrm{c}}$ Northeastern Plant Diagnostic Network (NEPDN): CT, DE, MA, MD, ME, NH, NJ, NY, PA, RI, VT, and WV.

${ }^{\mathrm{d}}$ North Central Plant Diagnostic Network (NCPDN): IA, IL, IN, MI, MO, MN, OH, and WI.

e Southern Plant Diagnostic Network (SPDN): AL, AR, FL, GA, KY, LA, MS, NC, SC, TN, TX*, VA, PR (Puerto Rico), and USVI (U.S. Virgin Islands). Within the NPDN, Texas (TX*) is split between GPDN and SPDN. To facilitate data management and to reflect the majority population density from which submissions were expected to occur, all TX records were tabulated within SPDN.

${ }^{f}$ Western Plant Diagnostic Network (WPDN): AK, AZ, CA, HI, ID, NM, NV, OR, UT, WA, AS (American Samoa).

${ }^{\mathrm{g}}$ Information provided about principal host plants does not reflect the documented range of possible host plants, and instead denotes the host plants that were most frequently indicated on data records that accompanied scale insect submissions. 
dissimilar life cycles. In turn, such knowledge can be used to adjust seasonal scouting efforts for crawler emergence and to optimize timing to treat infested and susceptible host plant materials in affected landscapes and nurseries. For those taxa with similar life history patterns among congeneric species, even a tentative or genus-level identification will enable state Extension specialists, nursery managers, and landscape management professionals to develop a more comprehensive action plan.

NPDN and state database records serve as a repository for information that can help identify the range of native and invasive species that are not previously known. Many of the mealybug identifications recovered in NDR represented CA records, where the management of species (including Ferrisia gilli Gullan, as well as the viruses that mealybugs can vector) is becoming increasingly challenging in viticulture (for example, Wunderlich et al. 2013). Although first detected in CT in 2014 (Miller et al. 2005), a recently published range for the Japanese maple scale, Lopholeucaspis japonica (Cockerell), includes AL, DE, GA, IN, KY, LA, MD, NC, NJ, NY, OH, PA, RI, TN, VA, and Washington, DC (Gill and Shrewsbury 2014). In addition to the above states and territories, NDR data (not shown) includes $L$. japonica records from CT (10 records), SC (8), MA (6), TX and WV (3 each), IL (2), and IA, MI, and NH (each with 1 record). NDR record entries do not contain information about establishment status of species (e.g., established, under management, or eradicated), including invasive insects. However, those states that yielded the most L. japonica reports (MD [137], VA [71], PA [55], DE [52], and NC and NY [each with 31 records]) are more likely to have established populations of the species.

Data can also be used to identify areas that are more likely to contain key scale insect infestations. As examples, records of $L$. japonica from NC and NY were submitted primarily from Mecklenburg (13), Wake (9), and Suffolk (21) counties, which correspond to Charlotte, NC; Raleigh, NC; and eastern Long Island, $\mathrm{NY}$, respectively. Using an area-wide approach, these locations could be surveyed to determine the degree of $L$. japonica establishment. If widespread, locations in these areas could be used to help assess the extent to which $L$. japonica interacts with specific host plants or natural enemies, including entomopathogenic agents, or how scale populations are influenced by urban environments. Similarly, states reporting small numbers of confirmed records and those with inconclusive identifications (e.g., OK with one "inconclusive" record of L. japonica) of invasive and economically or aesthetically important pest species provides a rationale for

\begin{tabular}{|c|c|c|c|c|c|c|c|c|}
\hline \multicolumn{9}{|c|}{$\begin{array}{l}\text { TABLE } 4 \\
\text { Twelve mealybug taxa (Hemiptera: Sternorrhyncha: Coccoidea: Pseudococcidae) ranking as the top } 10 \text { most frequent among } \\
\text { submissions to the National Plant Diagnostic Network (NPDN) and their respective regional data for submissions made between } \\
\text { about } 2005 \text { and } 2017\end{array}$} \\
\hline \multirow[b]{2}{*}{ Rank } & \multirow{2}{*}{$\begin{array}{l}\text { Species and taxonomic } \\
\text { authority }\end{array}$} & \multirow{2}{*}{$\begin{array}{l}\text { NPDN } \\
\text { sum }^{\mathrm{a}}\end{array}$} & \multicolumn{5}{|c|}{ Number of specimens (ID confirmed/suspected) } & \multirow[b]{2}{*}{ Principal host plant(s) indicated ${ }^{9}$} \\
\hline & & & GPDN $^{b}$ & NEPDNc & NCPDN $^{d}$ & SPDN $^{e}$ & WPDN ${ }^{f}$ & \\
\hline 1 & Phenacoccus sp. Cockerell & 1,331 & $1(0 / 1)$ & - & - & $1(1 / 0)$ & $1,329(1,329 / 0)$ & $\begin{array}{l}\text { Many euphorbs and deciduous } \\
\text { plants }\end{array}$ \\
\hline 3 & Pseudococcus sp. Westwood & 460 & $4(1 / 3)$ & $17(13 / 4)$ & $9(5 / 4)$ & $24(13 / 11)$ & $406(406 / 0)$ & $\begin{array}{l}\text { Many deciduous and broadleaf } \\
\text { evergreen plants }\end{array}$ \\
\hline 4 & Planococcus ficus (Signoret) & 166 & - & - & - & - & $166(166 / 0)$ & Many deciduous plants \\
\hline 5 & Antonina graminis (Maskell) & 136 & $1(1 / 0)$ & - & - & $117(91 / 26)$ & $18(18 / 0)$ & Many graminaceous plants \\
\hline 6 & $\begin{array}{l}\text { Pseudococcus longispinus } \\
\text { Targioni-Tozzetti }\end{array}$ & 83 & $5(2 / 3)$ & $10(6 / 4)$ & $6(6 / 0)$ & $18(14 / 4)$ & $44(44 / 0)$ & $\begin{array}{l}\text { Many interiorscape, deciduous, and } \\
\text { broadleaf evergreen plants }\end{array}$ \\
\hline 8 & $\begin{array}{l}\text { Pseudococcus maritimus } \\
\text { (Ehrhorn) }\end{array}$ & 68 & $1(0 / 1)$ & $2(1 / 1)$ & - & $1(1 / 0)$ & $64(64 / 0)$ & $\begin{array}{l}\text { "Cactus", “aroids", Gleditsia sp., } \\
\text { Prunus sp., Vitis sp. }\end{array}$ \\
\hline 9 & Ferrisia gilli Gullan & 24 & - & - & - & $1(1 / 0)$ & $23(23 / 0)$ & Myrica sp. \\
\hline 9 & $\begin{array}{l}\text { Nipaecoccus nipae } \\
\text { (Maskell) }\end{array}$ & 24 & - & $1(0 / 1)$ & $1(0 / 1)$ & - & $22(20 / 2)$ & "Palms", Psidium sp. \\
\hline 10 & $\begin{array}{l}\text { Ferrisia grassii virgata } \\
\text { (Cockerell) }\end{array}$ & 18 & $3(1 / 2)$ & $1(0 / 1)$ & - & $12(12 / 0)$ & $2(2 / 0)$ & $\begin{array}{l}\text { Many deciduous and broadleaf } \\
\text { evergreen plants }\end{array}$ \\
\hline
\end{tabular}

${ }^{a}$ NPDN maintains the National Data Repository (NDR) database that is a compilation of state-based submission records from plant pest and disease diagnostic clinics, including distance diagnostic submissions.

${ }^{\mathrm{b}}$ Great Plains Diagnostic Network (GPDN): CO, KS, MT, NE, ND, OK, SD, TX*, and WY.

${ }^{\mathrm{c}}$ Northeastern Plant Diagnostic Network (NEPDN): CT, DE, MA, MD, ME, NH, NJ, NY, PA, RI, VT, and WV.

${ }^{\mathrm{d}}$ North Central Plant Diagnostic Network (NCPDN): IA, IL, IN, MI, MO, MN, OH, and WI.

e Southern Plant Diagnostic Network (SPDN): AL, AR, FL, GA, KY, LA, MS, NC, SC, TN, TX*, VA, PR (Puerto Rico), and USVI (U.S. Virgin Islands). Within the NPDN, Texas (TX*) is split between GPDN and SPDN. To facilitate data management and to reflect the majority population density from which submissions were expected to occur, all TX records were tabulated within SPDN.

${ }^{f}$ Western Plant Diagnostic Network (WPDN): AK, AZ, CA, HI, ID, NM, NV, OR, UT, WA, AS (American Samoa).

${ }^{\mathrm{g}}$ Information provided about principal host plants does not reflect the documented range of possible host plants, and instead denotes the host plants that were most frequently indicated on data records that accompanied scale insect submissions.

${ }^{\text {h }}$ Tally includes four specimens identified as $P$. affinis, which is currently classified as $P$. viburni (Signoret); one specimen was submitted to the SPDN and three to the WPDN. 
Extension services and regulatory agencies in these states to allocate resources to assess the species' status and range. Updating the NDR database with historical and pre-NPDN records will be particularly helpful as archived information and state-based records that were collected prior to 2002 are made available electronically. In the future, records could also capture information that may be documented on specimen labels in collections and then within published reports. Notably, the NPDN is currently updating the requirements for data collection to include more detail from identifiers about their submissions, including confidence levels and methods associated with identifications, and efforts are underway to enable taxonomic identification training via webinar and online resources. The SPDN hub laboratory is scanning and collecting basic data on historic diagnoses and is enabling upload of data from entomology and nematology resources to the NDR. Prioritized lists from this analysis will benefit the NPDN and its clientele as it focuses training for diagnosticians and first detectors.

The usefulness of NDR records to elucidate patterns of distribution or spread of recently introduced scale insect species and to validate first detection dates reported in other resources is limited. For example, crapemyrtle bark scale, Acanthococcus lagerstroemiae (Kuwana), was first detected in TX in 2004 and was subsequently reported in OK (2011), LA (2012), GA (2013), TN (2013), AL (2014), AR (2014), NM (2014), VA (2014), MS (2015), NC (2016), WA (2016), KS (2019), SC (2019), and DE (2020) (EDDMapS 2020; Wang et al. 2016). The earliest records of $A$. lagerstroemiae that were included in NDR records and state diagnostic databases were 2013 for OK and TN, 2014 for AL, 2015 for AR, and 2016 for NC and LA, which do not align with other reported years of first detection. Similarly, the speed of spread of the cycad aulacaspis scale, Aulacaspis yasumatsui Takagi, on cycad cannot be well documented from database records. Among published reports, the dates of first $A$. yasumatsui detection were from FL in 1996 (Halbert 1996), HI in 1998 (Heu et al. 2003), around 2003 in CA (ISSG 2011), prior to 2006 in TX (Flores and Carlson 2009), and prior to 2012 in AL, GA, LA, and SC (Malumphy and Marquart 2012). Confirmed first detection records for states within the NDR are CA (2006), SC (2007), AL (2008), and LA and OK (both in 2013). Timeliness of submission into the NDR database may lag a year or more behind published reports. Consequently, there are missed public/private collaboration opportunities for first detectors of initial infestations, who are often research academics, to share their records with state diagnostic laboratories and also to log those incident records into the NDR database.

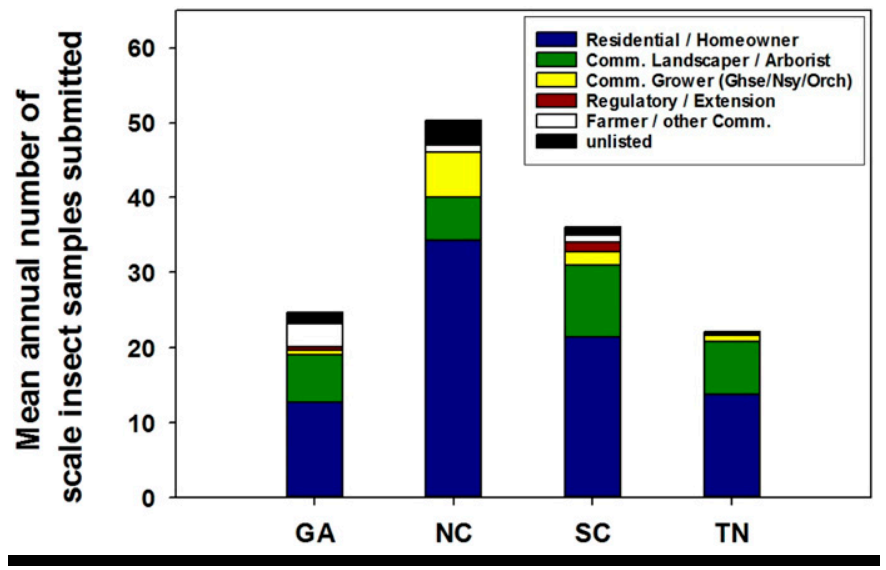

FIGURE 1

Annual mean numbers of scale insect samples submitted to four state diagnostic laboratories across nine common years (2008 to 2016). Bar colors within each state's column represent the mean proportion received from different client types that submitted the specimens for diagnostic identification.

TABLE $\mathbf{5}$
The top five other scale insect taxa (Hemiptera: Sternorrhyncha: Coccoidea) most frequently represented among submissions
to the National Plant Diagnostic Network (NPDN) and their respective regional data for submissions made between about
2005 and $\mathbf{2 0 1 7}$

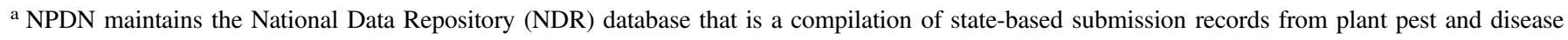
diagnostic clinics, including distance diagnostic submissions.

${ }^{\mathrm{b}}$ Great Plains Diagnostic Network (GPDN): CO, KS, MT, NE, ND, OK, SD, TX*, and WY.

${ }^{\mathrm{c}}$ Northeastern Plant Diagnostic Network (NEPDN): CT, DE, MA, MD, ME, NH, NJ, NY, PA, RI, VT, and WV.

${ }^{\mathrm{d}}$ North Central Plant Diagnostic Network (NCPDN): IA, IL, IN, MI, MO, MN, OH, and WI.

e Southern Plant Diagnostic Network (SPDN): AL, AR, FL, GA, KY, LA, MS, NC, SC, TN, TX*, VA, PR (Puerto Rico), and USVI (U.S. Virgin Islands). Within the NPDN, Texas (TX*) is split between GPDN and SPDN. To facilitate data management and to reflect the majority population density from which submissions were expected to occur, all TX records were tabulated within SPDN.

${ }^{\mathrm{f}}$ Western Plant Diagnostic Network (WPDN): AK, AZ, CA, HI, ID, NM, NV, OR, UT, WA, AS (American Samoa).

$\mathrm{g}$ Information provided about principal host plants does not reflect the documented range of possible host plants, and instead denotes the host plants that were most frequently indicated on data records that accompanied scale insect submissions. 
Finally, we found in this study that green industry professionals did not submit as many samples to the diagnostic services as would be expected, given the potential financial and operational benefits that would occur following diagnoses of an armored, soft, or other scale insect pest species infestation. A critical question remains: "Why are green industry professionals not utilizing pest diagnostic services more extensively?" Among data maintained by the four southeastern U.S. states, landscape care professionals and ornamental plant producers submitted on average just $29 \%$ of records examined. The limited use of services documented herein echoes the low numbers of yearly samples self-reported as submitted by green industry professionals (LeBude et al. 2012, 2017). Although these data do not inform why this resource-use gap persists, several reasons may be contributing factors. First, many diagnostic services developed a fee-based structure after about 2005, and some green industry professionals may consider diagnostic fees an unnecessary supplemental cost above and beyond costs associated with pesticide treatment. Next, green industry professionals also interact with Extension personnel (county Extension agents or state Extension specialists), private pest diagnosis services and consultants, their peers, and allied industry partners (e.g., representatives of pesticide manufacturers and dealers) directly (LeBude et al. 2012). Growers may be requesting assistance in pest identification and management recommendations through these channels to a greater degree than is presently recognized. Another possible cause for low sample submissions from growers could be that green industry professionals perceive that they already have sufficient experience in identifying scale insects to their most relevant taxonomic level or are adequately achieving management success through prior encounters and treatments. Anecdotal accounts from interactions with grounds managers and landscape professionals suggests that online identifications are made using Google image searches with few individuals familiar with more advanced identification resources like BugGuide.net or the Bugwood Image Database System (J.-H. Chong, unpublished data). Therefore, products that are developed using these survey results of the top scale insect pests are expected to extend beyond NDR users and the NPDN, helping to more efficiently reach a broader audience with target-specific detail and guidance.

Green industry professionals do rely heavily on online resources for information about plant pests (LeBude et al. 2012, 2017). Expecting that growers and landscape management professionals can directly benefit from access to resources that are specific to scale insect identification, collated and comprehensive identification and management aids would become indispensable tools for these and other users. Extension personnel, private diagnostic services, consultants, and allied industry partners who also face a lack of expertise in identifying scale insects are expected to use and benefit from the resource guides that are currently being developed based on the findings of this report. These guides will help users to identify and understand the life history, ecology, and management of the most prevalent scale insect pest species in the United States.

\section{Acknowledgments}

We appreciate permissions granted by state diagnostic data managers and the NPDN Executive Committee that enabled access to records from their respective databases. This article is Technical Contribution No. 6840 of the Clemson University Experiment Station.

\section{Literature Cited}

Ahmed, M. Z., and Miller, D. 2019. Chionaspis pinifoliae (Fitch) (Diaspididae: Coccomorpha, Hemiptera), pine needle scale, a potential pest of Florida pines and the Christmas tree industry, but not established in Florida. Florida
Department of Agriculture and Consumer Services FDACS-P-02132, Issue No. 443. https://www.fdacs.gov/content/download/89941/file/CIRCULARpine-needle-scale.pdf (accessed 22 July 2020).

Braman, S. K., Chappell, M. R., Chong, J.-H., Fulcher, A., Gauthier, N. W., Klingeman, W. E., and Knox, G., LeBude, A. V., Neal, J., White, S., Adkins, C., Derr, J., Frank, S., Hale, F., Hand, F. P., Marble, C., Williams-Woodward, J., and Windham, A. 2015. Pest management strategic plan for container and field-produced nursery crops: Revision 2015. A. V. LeBude and A. Fulcher, eds. Southern Region IPM Center, Raleigh, NC. https://ipmdata.ipmcenters.org/ documents/pmsps/SNIPMnurserycrops2015.pdf (accessed 18 March 2020).

Camacho, E. R., and Chong, J.-H. 2015. General biology and current management approaches for soft scale pests (Hemiptera: Coccidae). J. Integr. Pest Manag. 6:17.

Dale, A. G., and Frank, S. D. 2014. The effects of urban warming on herbivore abundance and street tree condition. PLoS One 9:e102996.

Dale, A. G., and Frank, S. D. 2018. Urban plants and climate drive unique arthropod interactions with unpredictable consequences. Curr. Opin. Insect Sci. 29:27-33.

Deng, J., Li, K., Chen, C., Wu, S., and Huang, X. 2016. Discovery pattern and species number of scale insects (Hemiptera: Coccoidea). PeerJ 4:e2526.

EDDMapS. 2020. Crapemyrtle bark scale, Acanthococcus lagerstroemiae (Kuwana). https://stopcmbs.com/crapemyrtle-bark-scale/monitoring/ (accessed 24 March 2020).

Flores, D., and Carlson, J. 2009. Fortuitous establishment of Rhyzobius lophanthae (Coleoptera: Coccinellidae) and Aphytis lingnanesis (Hymenoptera: Encyrtidae) in South Texas on the cycad aulacaspis scale, Aulacaspis yasumatsui (Hemiptera: Diaspididae). Southwest. Entomol. 34:489-492.

Frank, S. D. 2019. A survey of key arthropod pests on common southeastern street trees. Arboric. Urban For. 45:155-166.

Fulcher, A., Klingeman, W. E., Chong, J.-H., LeBude, A. V., Armel, G. R., Chappell, M., Frank, S., Hale, F., Neal, J., White, S., Williams-Woodward, J., Ivors, K., Adkins, C., Senesac, A., and Windham, A. 2012. Stakeholder vision of future direction and strategies for southeastern U.S. nursery pest research and Extension programming. J. Integr. Pest Manag. 3:D1-D8.

Garcia Morales, M., Denno, B. D., Miller, D. R., Miller, G. L., Ben-Dov, Y., and Hardy, N. B. 2016. ScaleNet: A literature-based model of scale insect biology and systematics. Database 2016:bav118.

Gill, S., and Shrewsbury, P. 2014. Japanese maple scale: A pest of nursery and landscape trees and shrubs. Fact Sheet FS-967. University of Maryland Extension, College Park, MD. https://extension.umd.edu:443/sites/extension.umd.edu/ files/_docs/publications/FS-967\%20Japanese\%20Maple\%20Scale.pdf (accessed 18 March 2020).

Halbert, S. E. 1996. Entomology section. Tri-ology 35:4-9.

Hamon, A. B., and Williams, M. L. 1984. The soft scale insects of Florida (Homoptera: Coccoidea: Coccidae). Arthropods of Florida and Neighboring Land Areas, Vol. 11. Contribution No. 600, Bureau of Entomology. Florida Department of Agriculture and Consumer Services, Division of Plant Industry, Gainesville, FL.

Hanks, L. M., and Denno, R. F. 1993. Natural enemies and plant water relations influence the distribution of an armored scale insect. Ecology 74:1081-1091.

Hardy, N. B. 2013. The status and future of scale insect (Coccoidea) systematics. Syst. Entomol. 38:453-458.

Heu, R. A., Chun, M., and Nagamine, W. T. 2003. Sago palm scale, Aulacaspis yasumatsui Takagi. New Pest Advisory No. 99-01. State of Hawaii. Department of Agriculture, Honolulu, HI. https://hdoa.hawaii.gov/pi/files/2013/ 01/npa99-01-spalmscale2.pdf (accessed 18 March 2020).

Invasive Species Specialist Group (ISSG). 2011. Global Invasive Species Database. http://www.iucngisd.org/gisd/ (accessed 18 March 2020).

Kosztarab, M. 1997. Ornamentals and house plants. Pages 357-366 in: Soft Scale Insects: Their Biology, Natural Enemies and Control, Vol. 7B. Y. Ben-Dov and C. J. Hodgson, eds. Elsevier Science, Amsterdam, The Netherlands.

LeBude, A., White, S., Fulcher, A., Frank, S., Klingeman, W., Chong, J. C., Chappell, M., Windham, A., Braman, K., Hale, F., Dunwell, W., WilliamsWoodward, J., Ivors, K., Adkins, C., and Neal, J. 2012. Assessing the integrated pest management practices of southeastern U.S. ornamental nursery operations. Pest Manag. Sci. 68:1278-1288.

LeBude, A. V., Fulcher, A., Dubois, J.-J., Braman, S. K., Gauthier, N., Neal, J., Chappell, M., Fulcher, A., Klingeman, W. E., Hale, F. A., Knox, G., Neal, J., and Windham, A. S. 2017. Experiential nursery integrated pest management workshop series to enhance grower practice adoption. HortTechology 27:772-781.

Malumphy, C., and Marquart, C. 2012. Queen sago palm (Cycas circinalis L.) killed by Asian cucad scale Aulacaspis yasumatsui Takagi (Hemiptera: Diaspididae) in Britain. Entomol. Mon. Mag. 148:147-154.

Maw, H. E. L., Foottit, R. G., Hamilton, K. G. A., and Scudder, G. C. E. 2000. Checklist of the Hemiptera of Canada and Alaska. NRC Research Press, Ottawa, ON.

Miller, D. R., and Davidson, J. A. 2005. Armored Scale Insect Pests of Trees and Shrubs (Hemiptera: Diaspididae). Comstock Publishing, Cornell University Press, Ithaca, NY. 
Miller, D. R., Miller, G. L., Hodges, G. S., and Davidson, J. A. 2005. Introduced scale insects (Hemiptera: Coccoidea) of the U.S. and their impact on U.S. agriculture. Proc. Entomol. Soc. Wash. 107:123-158.

Nakahara, S. 1981. List of the Hawaiian Coccoidea (Hemiptera: Sternorhyncha). Proc. Hawaii. Entomol. Soc. 23:387-424.

National Plant Diagnostic Network (NPDN). 2018a. National Plant Diagnostic Network website. https://www.npdn.org/home (accessed 18 March 2020).

National Plant Diagnostic Network (NPDN). 2018b. First detector training and information. https://www.npdn.org/first_detector (accessed 18 March 2020).

Oetting, R. D., Hudson, W., and Braman, S. K. 2007. Ornamentals, lawn and turf insects. Pages 20-22 in: Summary of Losses from Insect Damage and Cost of Control in Georgia 2004. P. Guillebeau, N. Hinkle, and P. Roberts, eds. Miscellaneous Publication Number 106. University of Georgia Cooperative Extension Service, Athens, GA.

Quesada, C. R., and Sadof, C. S. 2017. Efficacy of horticultural oil and insecticidal soap against selected armored and soft scales. HortTechnology 27: 618-624.

Quesada, C. R., Witte, A., and Sadof, C. S. 2018. Factors influencing insecticide efficacy against armored and soft scales. HortTechnology 28:267-275.
Raupp, M., Koehler, C., and Davidson, J. 1992. Advances in implementing integrated pest management for woody landscape plants. Annu. Rev. Entomol. 37:561-585. https://doi.org/10.1146/annurev.en.37.010192. 003021

Stack, J. P., Bostock, R. M., Hammerschmidt, R., Jones, J. B., and Luke, E. 2014. The National Plant Diagnostic Network: Partnering to protect plant systems. Plant Dis. 98:708-715.

Tooker, J. F., and Hanks, L. M. 2000. Influence of plant community structure on natural enemies of pine needle scale (Homoptera: Diaspididae) in urban landscapes. Environ. Entomol. 29:1305-1311.

Wang, Z., Chen, Y., Gu, M., Vafaie, E., Merchant, M., and Diaz, R. 2016. Crapemyrtle bark scale: A new threat for crapemyrtles, a popular landscape plant in the U.S. Insects 7:78

Wunderlich, L. R., Cooper, M. L., and Daane, K. M. 2013. Seasonal biology of Ferrisia gilli (Hemiptera: Pseudococcidae) in California Sierra foothill vineyards. J. Econ. Entomol. 106:1716-1725.

Youngsteadt, E., Dale, A. G., Terando, A. J., Dunn, R. R., and Frank, S. D. 2015. Do cities simulate climate change? A comparison of herbivore response to urban and global warming. Glob. Change Biol. 21:97-105. 